\title{
PRESERVACIÓN CON CELSIOR EN TRASPLANTE RENAL. NUESTRA EXPERIENCIA
}

\author{
P. PÉREZ SANZ, F.J. BURGOS REVILLA*, R. MARCÉN LETOSA**, \\ J. PASCUAL SANTOS**, J.L. MERINO RIVAS**, J. ORTUÑO MIRETE** \\ Servicio de Urología. Hospital Ramón y Cajal. Madrid. *Dpto. Ciencias Morfológicas y Cirugía. Universidad \\ Alcalá de Henares. Madrid. **Servicio de Nefrología. Hospital Ramón y Cajal. Madrid.
}

Actas Urol Esp. 28 (1): 49-53, 2004

\section{RESUMEN}

PRESERVACIÓN CON CELSIOR EN TRASPLANTE RENAL. NUESTRA EXPERIENCIA

OBJETIVOS: Analizar comparativamente la incidencia de necrosis tubular aguda (NTA) y función del injerto renal según el líquido de preservación empleado. Wisconsin vs Celsior.

MATERIAL Y MÉTODOS: Desde enero de 1994 a diciembre de 2002 se implantaron 229 injertos renales, 190 de ellos preservados con Wisconsin (82,9\%) y 39 con Celsior $(17,1 \%)$. En este trabajo, tras comprobar la homogeneidad estadística de ambos grupos, se analiza comparativamente la incidencia de NTA y la evolución de la creatinina sérica en función del líquido de preservación empleado.

RESULTADOS: No hay diferencia significativa en la incidencia de NTA entre los grupos Celsior (23\%) y Winsconsin (36\%). Se obtiene resultado similar en proporción de NTA en el subgrupo de injertos con periodos de isquemia fría superior a $12 \mathrm{~h}$, con independencia del líquido de preservación empleado. El grupo Celsior presenta menores niveles de creatinina sérica a 1, 3, 6 y 12 meses postransplante renal, con una diferencia estadística significativa $(\mathrm{p}<0,05)$.

CONCLUSIONES: La preservación renal con Celsior proporciona resultados equivalentes a Wisconsin en relación a incidencia de NTA y función renal, con la ventaja de un menor coste.

PALABRAS CLAVE: Trasplante renal. Preservación renal. Celsior.

\section{ABSTRACT}

CELSIOR'S KIDNEY PRESERVATION IN RENAL TRANSPLANTATION. OUR EXPERIENCE

BACKGROUND: The goal of this research is to make a comparative analysis of acute tubular necrosis (NTA) incidence in function of preservation solution used: Wisconsin vs Celsior.

METHODS: From january 1994 to december 2002, 229 kidney transplantation procedures were executed; 190 of them were perfused with Winsconsin (82.9\%) and 39 with Celsior (17.1\%). After checking the statistical homogeneity of both groups, we analysis comparativily the incidence of NTA and the evolution of serum creatinine in function of preservation solution utilized.

RESULTS: There was not statistical significant difference in NTA incidence between Celsior (23\%) and Wisconsin group (36\%).

We assesed that each group were comparable with regard to NTA incidence of subgroups with cold ischemia times longer 12 hours.

Creatinine serum in Celsior group tended to be lower than Wisconsin group at 1, 3, 6 and 12 months postransplantation (statistically significant difference, $\mathrm{p}<0.05$ )

CONCLUSIONS: Kidney preservation in Celsior solution provides similar results to the ones obtained in Wisconsin solution in relation with NTA incidence and kidney function with the added advantage of a lower cost.

KEY WORDS: Renal transplantation. Renal preservation. Celsior. 
$\mathrm{E}_{\mathrm{n}}^{1}$ objetivo de la preservación del injerto es mantener la integridad estructural y funcional del órgano, prolongando la tolerancia a los daños de la isquemia-reperfusión con minimización del retraso en la función del injerto, consiguiendo tiempo suficiente para compartir los órganos entre diferentes centros de transplan$\mathrm{te}^{1,2}$.

La solución de Belzer (U. Winsconsin) es en la actualidad el líquido de elección en la preservación hepática, pancreática y renal. La solución Celsior comenzó a utilizarse como líquido de preservación de órganos intratorácicos (corazón y pulmón). Su aplicación se extendió a trasplante hepático y experimental renal, demostrándose una eficacia similar en comparación con otras soluciones de preservación como Wisconsin ${ }^{4-6}$.

La solución Celsior proporciona las ventajas de un potente buffer (histidina) así como una alta concentración en sodio y baja en potasio, lo que le convierte en única ${ }^{3}$. Así mismo tiene una baja viscosidad $\mathrm{y}$ menor coste, ventajas adicionales frente a la solución Wisconsin ${ }^{6}$ (Tabla I).

Dado que encontramos escasas publicaciones que nos informen acerca de la seguridad como líquido de preservación renal del Celsior, decidimos analizar comparativamente la incidencia de

\section{TABLA I}

COMPOSICIÓN LÍGUIDO DE PERFUSIÓN

\begin{tabular}{||l|c|c||}
\hline Composición & Wisconsin & Celsior \\
\hline Sodio & $30 \mathrm{mmol} / \mathrm{dl}$ & $100 \mathrm{mmol} / \mathrm{dl}$ \\
\hline Potasio & $120 \mathrm{mmol} / \mathrm{dl}$ & $15 \mathrm{mmol} / \mathrm{dl}$ \\
\hline Magnesio & $5 \mathrm{mmol} / \mathrm{dl}$ & $13 \mathrm{mmol} / \mathrm{dl}$ \\
\hline Calcio & - & $0,25 \mathrm{mmol} / \mathrm{dl}$ \\
\hline Sulfato & $5 \mathrm{mmol} / \mathrm{dl}$ & - \\
\hline Lactobionato & $100 \mathrm{mmol} / \mathrm{dl}$ & $80 \mathrm{mmol} / \mathrm{dl}$ \\
\hline Rafinosa & $30 \mathrm{mmol} / \mathrm{dl}$ & - \\
\hline Hidroxietil & $50 \mathrm{gr} / \mathrm{dl}$ & - \\
\hline Fosfato & $25 \mathrm{mmol} / \mathrm{dl}$ & - \\
\hline Glutation & $3 \mathrm{mmol} / \mathrm{dl}$ & $3 \mathrm{mmol} / \mathrm{dl}$ \\
\hline Adenosina & $5 \mathrm{mmol} / \mathrm{dl}$ & - \\
\hline Alopurinol & $1 \mathrm{mmol} / \mathrm{dl}$ & - \\
\hline Manitol & - & $20 \mathrm{mmol} / \mathrm{dl}$ \\
\hline Histidina & - & - \\
\hline Glutamato & - & - \\
\hline
\end{tabular}

necrosis tubular aguda (NTA) y evolución de la creatinina sérica de nuestros injertos renales en función del líquido de preservación (Celsior frente a Wisconsin). En la literatura está descrito que el papel del líquido de preservación tendría mayor peso en aquellos injertos con tiempos de isquemia prolongados ${ }^{6}$. Analizamos por este motivo la incidencia de NTA en relación con el tiempo de isquemia prolongado (superior a 12 horas) en ambos grupos.

\section{MATERIALES Y MÉTODOS}

Se lleva a cabo un estudio retrospectivo durante el periodo comprendido entre enero de 1994 a diciembre de 2002. Se practicaron 229 trasplantes renales, 190 de ellos preservados en Wisconsin $(82,9 \%)$ frente a 39 preservados con Celsior $(17,1 \%)$.

El análisis estadístico demográfico entre ambos grupos (edad, sexo, tiempo en diálisis del receptor; edad, sexo, incidencia de muerte traumática y tiempo en UVI del receptor) no demostró diferencias significativas (Tabla II). Datos quirúrgicos como el tipo de extracción, tiempo de isquemia fría y tiempo de anastomosis tampoco diferían significativamente (Tabla III).

\section{TABLA II}

DATOS DEMOGRÁFICOS

\begin{tabular}{|l|c|c|c|}
\hline & Wisconsin & Celsior & Significación \\
\hline $\begin{array}{l}\text { Edad receptor } \\
\text { (años) }\end{array}$ & $47,5 \pm 14$ & $43,2 \pm 13$ & n.s \\
\hline Sexo receptor: & & & \\
\hline \multicolumn{1}{|c|}{ Hombre } & 55,2 & 44,2 & n.s \\
\hline \multicolumn{1}{|c|}{ Mujer } & 44,8 & 55,8 & \\
\hline $\begin{array}{l}\text { T. diálisis } \\
\text { (meses) }\end{array}$ & 13,17 & 12,6 & n.s \\
\hline $\begin{array}{l}\text { Edad donante } \\
\text { (años) }\end{array}$ & $42,8 \pm 17,16$ & $38,1 \pm 12,5$ & n.s \\
\hline Sexo donante: & 54,7 & 43,6 & n.s \\
\hline \multicolumn{1}{|c|}{ Hombre } & 45,3 & 56,4 & n.s \\
\hline \multicolumn{1}{|c|}{ Mujer } & 45,8 & 28,6 & n.s \\
\hline $\begin{array}{l}\text { Muerte traumt. } \\
\text { (\%) }\end{array}$ & $3,6 \pm 2,3$ & $3,4 \pm 2,8$ & n.s \\
\hline $\begin{array}{l}\text { T. UVI donante } \\
\text { (días) }\end{array}$ & & & \\
\hline
\end{tabular}


TABLA III

DATOS QUIRÚRGICOS

\begin{tabular}{|l|c|c|c|}
\hline & Wisconsin & Celsior & Significación \\
\hline $\begin{array}{l}\text { Tipo } \\
\text { extracción (\%): }\end{array}$ & 5,6 & 2,8 & n.s \\
\hline Aislada & 94,4 & 97,2 & n.s \\
\hline Multiextracc. & $17,5 \pm 4,2$ & $16,9 \pm 3,7$ & n.s \\
\hline $\begin{array}{l}\text { T. isquemia } \\
\text { fria (h) }\end{array}$ & $38,8 \pm 11,4$ & $38,2 \pm 8,9$ & n.s \\
\hline $\begin{array}{l}\text { T. } 2^{\text {a }} \text { isq. } \\
\text { caliente (min) }\end{array}$ & & & \\
\hline
\end{tabular}

\section{RESULTADOS}

El grupo Celsior presenta una incidencia de NTA de $23 \%$ frente al grupo Wisconsin, de 36\%, sin diferencia significativa entre ambos (Fig. 1).

En ambos grupos se encuentra porcentaje similar de injertos con tiempos de isquemia superior a 12 horas $(71,8 \%$ en el grupo Celsior vs $81,5 \%$ en el grupo Wisconsin), sin una diferencia significativa. Tampoco el análisis comparativo de la incidencia de NTA en los subgrupos de injertos con isquemia fría prolongada demostró diferencia con independencia del líquido de preservación empleado, con cifras de NTA de 33\% en grupo Wisconsin frente 28,5 en Celsior (Fig. 2).

El análisis del descenso de la creatinina sérica en ambos grupos de injertos, objetivó una ventaja significativa estadísticamente para el grupo Celsior, con menores niveles al primer mes (con $\mathrm{p}<0,001), 3,6$ y 12 meses post-trasplante $(\mathrm{p}<0,05)$ (Tabla IV).

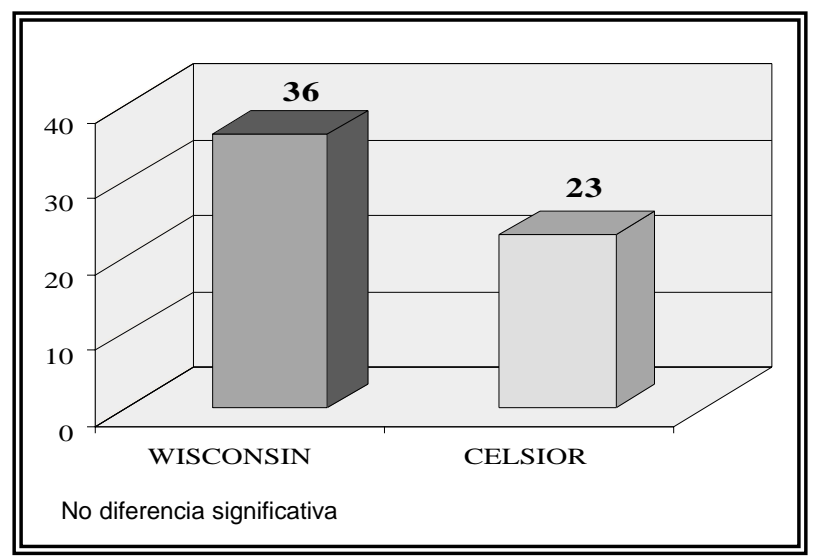

FIGURA 1. Incidencia necrosis tubular aguda (\%).

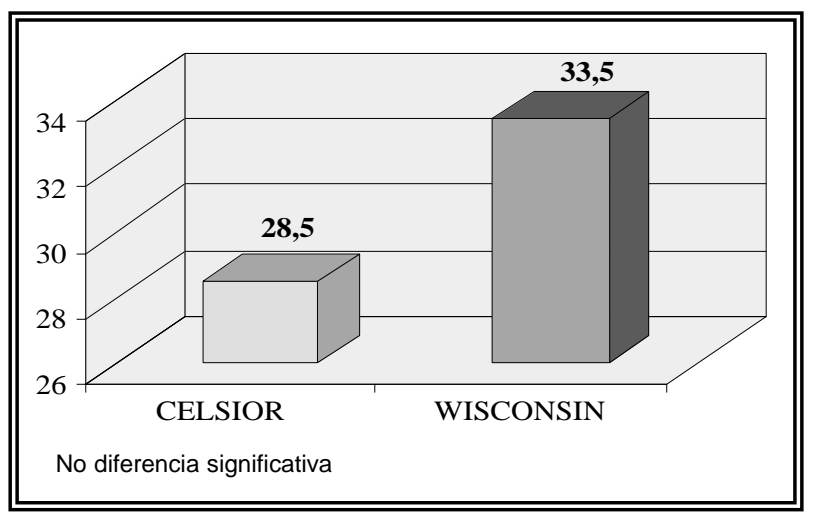

FIGURA 2. NTA en GR isquemia fria prolongada.

\section{TABLA IV}

CREATININA SÉRICA POST-TRASPLANTE (mlg/dl)

\begin{tabular}{|l|c|c|c|}
\hline & Wisconsin & Celsior & Significación \\
\hline $1 \mathrm{~m}$ & $1,94 \pm 0,90$ & $1,55 \pm 0,45$ & $\mathrm{p} 0,001$ \\
\hline $3 \mathrm{~m}$ & $1,7 \pm 0,50$ & $1,5 \pm 0,5$ & $\mathrm{p} 0,05$ \\
\hline $6 \mathrm{~m}$ & $1,6 \pm 0,50$ & $1,4 \pm 0,5$ & $\mathrm{p} 0,05$ \\
\hline $12 \mathrm{~m}$ & $1,57 \pm 0,04$ & $1,35 \pm 0,09$ & $\mathrm{p} 0,05$ \\
\hline
\end{tabular}

\section{DISCUSION}

La solución Celsior se aplicó inicialmente como líquido de preservación de órganos intratorácicos (corazón y pulmón). Su uso se extendió a trasplante hepático a nivel clínico y a nivel experimental renal, demostrándose una eficacia similar en comparación con otras soluciones de preservación como Wisconsin ${ }^{4-6}$.

Existen escasas referencias en la literatura acerca de su empleo en el trasplante renal. El único estudio prospectivo multicéntrico randomizado es descrito por Faenza et al. ${ }^{6}$, donde tras registrar los datos suministrados por cuatro centros de trasplante renal (Parma, Pisa, Modena y Bolonia) se llega a la conclusión de que los injertos cuyo líquido de preservación fue Celsior presentan semejantes tasas de diálisis post-operatoria, retorno a función normal del injerto y tasa de supervivencia a los dos años que aquellos injertos preservados con Wisconsin.

En el análisis del presente estudio no encontró una diferencia significativa en la incidencia de NTA global, ni en el subgrupo con tiempos de isquemia fría superior a 12 horas. Uno de los factores que justificaría este retraso en la función 
del injerto en el grupo Winsconsin frente al Celsior, sería el factor inmunológico o incidencia de rechazo agudo (R.A). Efectivamente el grupo de injertos preservados con Celsior presentó porcentaje inferior de RA $(2,56 \%)$ frente a los injertos preservados con Winsconsin $(22,6 \%$ de R.A) con una diferencia significativa ( $\mathrm{p}<0,001)$ (Fig. 3).

A pesar de que el patrón de inmunosupresión empleado es homogéneo estadísticamente hablando en ambos grupos desde 1997 (Fig. 4), eliminándose así el sesgo que provocaría este factor, se mantiene un mayor porcentaje de RA en el grupo Wisconsin frente al Celsior $(16,7 \%$ Wisconsin vs $2,56 \%$ Celsior, p<0,05) (Fig. 5).

\section{CONCLUSIONES}

Concluimos que, en nuestra experiencia, el empleo de la solución Celsior es tan segura como Wisconsin en cuanto a las tasas de NTA y función del injerto, con ventaja adicional de menor coste.

La incidencia superior de RA en el grupo Wisconsin frente al de Celsior no es justificable por el protocolo de inmunosupresión empleado durante este periodo. Deberían buscarse otros mecanismos por los cuales el líquido de preservación influiría en la respuesta del injerto al sistema inmune. Caería en el terreno de la especulación el señalar un cierto papel citoprotector del líquido de preservación ${ }^{7}$.

La mejor función del injerto durante el primer año post-trasplante en el grupo Celsior podría, por tanto, explicarse por esta diferencia de rechazo agudo, sin descartar otros factores aún no esclarecidos $^{8-10}$.

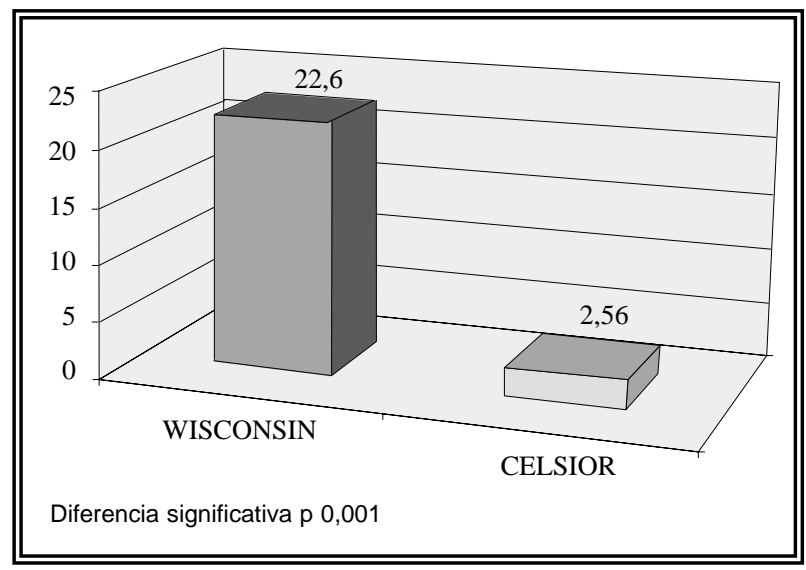

FIGURA 3. Rechazo agudo (porcentaje).

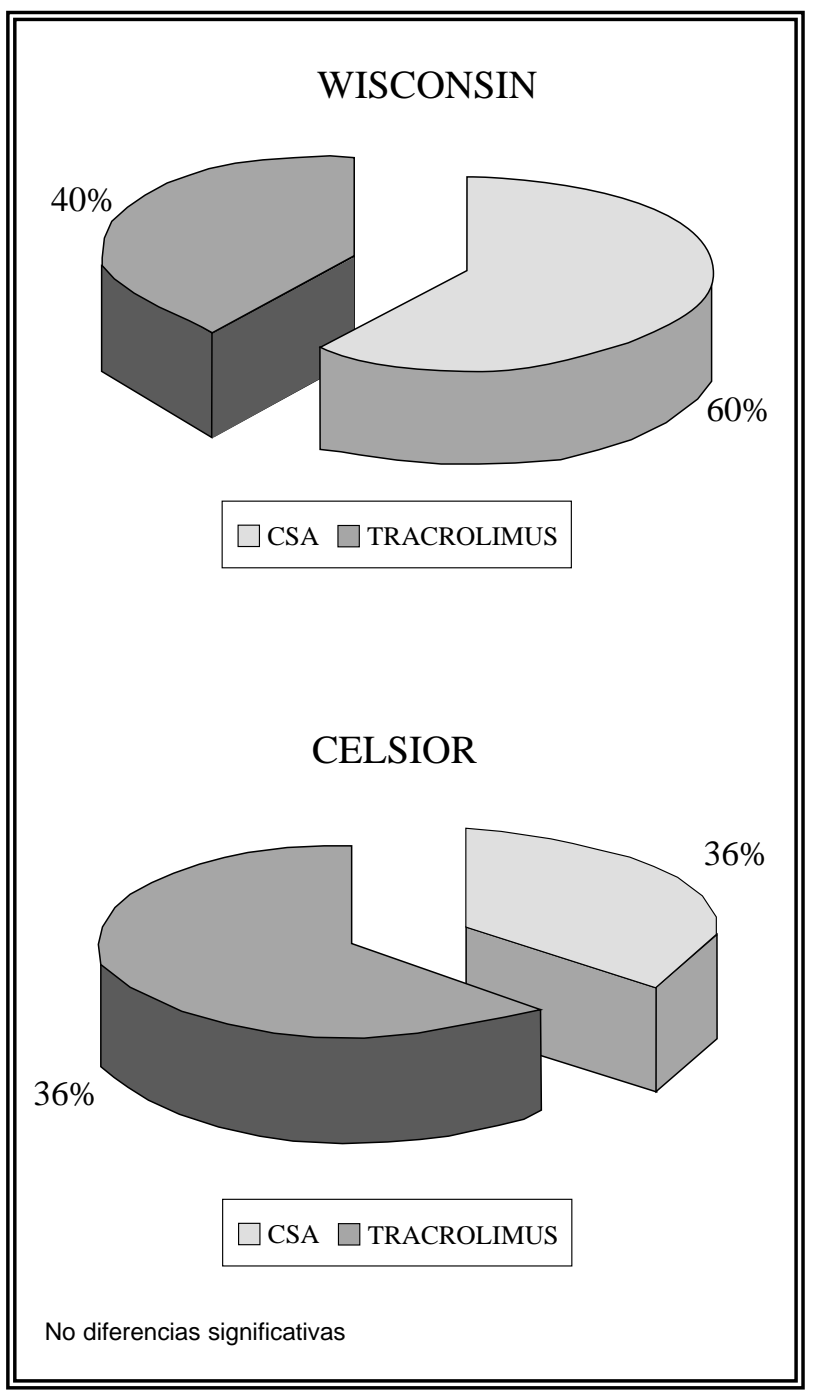

FIGURA 4. Inmunosupresión desde 1997.

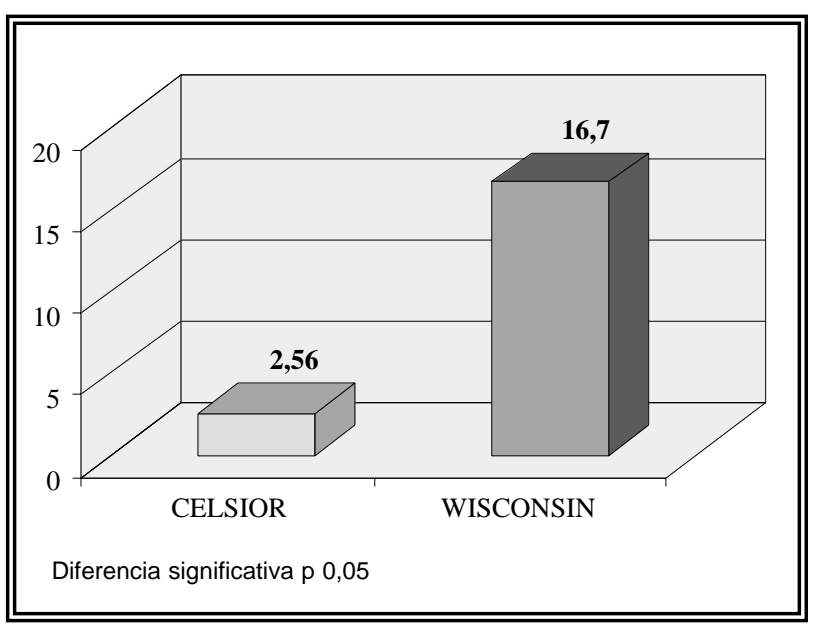

FIGURA 5. Rechazo agudo desde 1997 (porcentaje). 


\section{REFERENCIAS}

1. BARRY JM, CONLIN MJ.: El trasplante renal. Primera parte: preparación del receptor y donación de riñones. Conservación clínica de los riñones. AUA Update Series 2000. Lecciones 31-40: 93-95.

2. BARRY JM.: Renal transplantation. Kidney preservation. Campbell’s Urology, 8o edition: 354-57.

3. MUHLBACHER F, LANGER F, MITTERMAYER C.: Preservation solutions for transplantation. Transplant Proc 1999; 31 (5): 2069-2070.

4. BALDAN N, TOFFANO $\mathrm{M}$, CADROBBI $\mathrm{R}$ et al.: Kidney preservation in pigs using celsior, a new organ preservation solution. Transplant Proc 1997; 29 (8): 3539-3540.

5. NARDO B, CATENA F, CALLAVARI G et al.: Randomized clinical study comparing UW and Celsior solution in liver preservation for transplantation: preliminary results. Transplant Proc 2001; 33 (1-2): 870-872.

6. FAENZA A, CATENA F, NARDO B et al.: Kidney preservation with university of Wisconsin and Celsior solution: a prospective multicenter randomized study. Transplantation 2001; 1572 (7): 1274-1277.
7. SHOSKES DA, CECKA JM.: Effect of preservation and recipient inmune factors on delayed graft function in cadaveric renal transplantation. Transplant Proc 2001; 33 (6): 2967.

8. LECHEVALLIER E, DUSSOL B, LUCCIONI et al.: Postransplantation acute tubular necrosis: risk factors and implications for graft survival. Am $J$ Kidney Dis 1998; 32 (6): 984-991.

9. OJO AO, WOLFE RA, HELD PJ, PORT FJ, SCHMOUDER RL.: Delayed graft function: risk factor and implications for renal allograft survival. Transplantation 1997; 15; 63 (7): 968-974.

10. GIL VERNET S.: Insuficiencia renal aguda en el trasplante de órganos. Fracaso renal agudo. Edit Springer-Verlag Iberica, 1999: 119-126.

Dra. Pilar Pérez Sanz

C/ Ramón Pérez de Ayala, 92 - 10 C 28038 Madrid

(Trabajo recibido el 2 septiembre 2003) 